\title{
ALIANZAS EFÍMERAS: IZQUIERDAS \\ Y NACIONALISMO REVOLUCIONARIO \\ EN LA REVISTA POLÍTICA. \\ QUINCE DÍAS DE MÉXICO Y DEL MUNDO \\ $(1960-1962)^{1}$
}

\author{
Beatriz Urías Horcasitas \\ Universidad Nacional Autónoma de México
}

JEAN-PAUL SARTRE Y FERNANDO BENÍTEZ

F n 1960, Fernando Benítez publicó un reportaje acerca de la Crevolución cubana en un libro - La batalla de Cuba- que incluyó también un ensayo de Enrique González Pedrero. ${ }^{2} \mathrm{La}$ aparición de este libro coincidió con la de una serie de artículos escritos por Jean-Paul Sartre en el periódico France Soir bajo el título de "Ouragan sur le sucre" ("Huracán sobre el azúcar"). ${ }^{3}$

Fecha de recepción: 15 de noviembre de 2017

Fecha de aceptación: 21 de marzo de 2018

\footnotetext{
${ }^{1}$ Esta investigación fue apoyada por el programa PASPA-DGAPA-UNAM. Agradezco los comentarios que Roger Bartra y Gilles Bataillon hicieron a versiones preliminares de este trabajo. Asimismo, quedo agradecida a Rebeca de Gortari y a Francisco González Ayerdi por haberme permitido consultar su colección de Política.

2 Benítez, "La batalla de Cuba". El libro de Benítez fue la primera publicación de Ediciones Era en la colección Ancho Mundo. Acerca de la historia de Ediciones Era véase Reyes PéREz, "El sueño mayor de hacer libros".

3 SARTRE, "Ouragan sur le sucre".
} 
Ambos textos hicieron una apología de la revolución cubana y exaltaron la figura de Fidel Castro en el contexto de la Guerra Fría. Uno y otro fueron escritos en un momento de gran efervescencia política, marcada por el surgimiento de una corriente que se conoció en el ámbito internacional como la Nueva Izquierda.

La coincidencia temática y cronológica de estos dos textos pone de manifiesto el entusiasmo suscitado por la revolución cubana en la izquierda intelectual a nivel internacional; $y$, a la vez, encubre las diferencias profundas entre las corrientes políticas que asumieron el discurso de la revolución tercermundista al inicio de los años sesenta. Es decir, más allá de las similitudes entre ambos reportajes, sería difícil establecer paralelismos entre las trayectorias políticas e intelectuales de Jean Paul Sartre ${ }^{4}$ y Fernando Benítez. ${ }^{5}$ A lo cual hay que añadir que la percepción que uno y otro tuvieron de la revolución cubana no fue la misma. Al igual que otros simpatizantes de la Nueva Izquierda europea o estadounidense, Sartre vio en la revolución cubana una utopía irrealizable en el mundo capitalista. En un libro reciente acerca de la Nueva Izquierda neoyorkina, Rafael Rojas señala que ésta viajó a Cuba para "documentar la utopía"

\footnotetext{
${ }^{4}$ Sartre jugó un papel importante en la reconfiguración de la izquierda francesa a partir de los años cincuenta y mantuvo siempre una postura crítica ante las instituciones políticas. Entre 1952 y 1956, fue un "compañero de viaje" que apoyó abiertamente a la Unión Soviética e hizo propaganda del régimen en el extranjero. Tempranamente militó a favor de la independencia de Argelia, y en septiembre de 1961 publicó su controvertido "Prefacio" al libro Los condenados de la tierra, de Frantz Fanon, en el que hizo un llamado a favor de la liberación de los pueblos colonizados por medio de la violencia. SARTRE, "Préface à l'édition de 1961".

${ }^{5}$ El periodista y escritor mexicano Fernando Benítez fue un promotor cultural ligado al nacionalismo revolucionario. Como ensayista, editor de suplementos y colaborador en varias revistas estuvo a la cabeza de un grupo de escritores que adoptó las causas de la revolución cubana, el tercermundismo y la lucha contra el imperialismo, manteniendo siempre un vínculo estrecho con Cárdenas. Benítez, Lázaro Cárdenas y la Revolución mexicana.
} 
e intentar profundizar el proyecto descolonizador del Tercer Mundo en los años de la Guerra Fría. Al mismo tiempo, esta izquierda vanguardista pasó por alto el hecho de que los ideales libertarios y de moral sexual que estaban siendo reivindicados en las sociedades capitalistas estaban ausentes en Cuba. ${ }^{6}$ Desde una perspectiva muy diferente, Fernando Benítez y los nacionalistas revolucionarios vieron en la revolución cubana la imagen invertida de la mexicana, así como la apertura de una vía de transformación cercana al cardenismo. Para ellos, Cuba catalizó descontentos con la política interna y generó una nueva forma de crítica a la realidad nacional.

Partiendo del reconocimiento de que la izquierda intelectual que asumió la propuesta tercermundista y antiimperialista en los años sesenta no puede ser considerada como una unidad homogénea, este ensayo examina los dos primeros años de la revista Política. Quince días de México y del mundo (1960 a 1962). Se trata de una publicación de suma importancia que constituyó un parteaguas en la historia intelectual mexicana. En primer lugar, por haber nacido de la convergencia de muy diversas tendencias políticas, lo cual permitió que la revista incluyera a miembros del Partido Comunista, funcionarios gubernamentales, algunos lombardistas, así como a numerosos científicos sociales y escritores independientes, afines al nacionalismo revolucionario y al cardenismo. ${ }^{7}$ En segundo lugar, porque Política inauguró una nueva forma de crítica política que adaptó

\footnotetext{
${ }^{6}$ Rojas, Traductores de la utopía, pp. 35-37.

7 Carlos Illades explica la alianza coyuntural de estas tendencias al inicio de los años sesenta en los siguientes términos: "De igual forma que en la década de 1930, la izquierda nacionalista y los comunistas hicieron un pacto tácito, no solo para apoyar la revolución cubana, sino para reconfigurar el rumbo de la propia. A final de cuentas, el sesgo antiimperialista de ambas fue el elemento fundamental que los acercó durante un breve tiempo y no un culto innato a la violencia. Fue en otros espacios políticos, y sobre todo después del movimiento estudiantil, donde la opción cubana resonaría por la vía armada". ILLADES, "El compromiso de los intelectuales", pp. 33-34.
} 
la propuesta tercermundista y antiimperialista al análisis de la revolución mexicana, tomando siempre en cuenta el contexto internacional. Esta investigación plantea que, más allá de que su participación en Política supuso la adhesión a dicha propuesta, los periodistas, políticos e intelectuales que coincidieron en este proyecto no siempre compartieron la misma visión del cambio ni tuvieron las mismas expectativas. Entre ellos se encontraban científicos sociales marxistas como Narciso Bassols; escritores nacionalistas revolucionarios como Fernando Benítez y Carlos Fuentes; ${ }^{8}$ artistas plásticos estalinistas como David Alfaro Siqueiros; jóvenes funcionarios de filiación priista como Enrique González Pedrero; intelectuales críticos que no estaban afiliados al Partido Comunista y que tenían una trayectoria política e intelectual singular, como es el caso de Eli de Gortari; 9 y, finalmente, individuos como Jorge Carrión y Emilio Uranga, que habían formado parte del grupo Hiperión. ${ }^{10}$ Algunos de estos autores escribieron simultáneamente en El Espectador (1959-1960) (Luis Villoro, Francisco López Cámara, Jaime García Terrés, Carlos Fuentes) y en el suplemento La Cultura en México de la revista Siempre! (1962-1973), durante el periodo en que estuvo dirigido por Fernando Benítez.

Las tensiones derivadas de la coexistencia de tendencias políticas e ideológicas tan diversas provocaron escisiones y rupturas. A mediados de 1964, algunos de los nacionalistas revolucionarios con mayor visibilidad -Carlos Fuentes, Fernando Benítez, Víctor Flores Olea, Enrique González Pedrero y Francisco López Cámara- dejaron de escribir en Política por considerar que ésta se había radicalizado de más y que era necesario influir directamente en las decisiones del gobierno. En 1965, Alonso Aguilar,

\footnotetext{
8 Véase Enríquez Perea, "En Política: El periodismo militante de Carlos Fuentes".

9 Véase Chávez Mancilla, "De la Nicolaíta al 68. Eli de Gortari y la protesta universitaria”.

10 Véase Santos Ruíz, Los hijos de los dioses.
} 
Fernando Carmona y Enrique Ramírez y Ramírez también rompieron con la revista, para animar años más tarde Estrategia. Revista de análisis político (1974-1988).

¿Cuáles fueron en el inicio los puntos que hicieron coincidir grupos y tendencias tan diversas? En primer lugar, la convicción de que era necesario construir un espacio de crítica política, inexistente en México en aquellos años. Por otra parte, en el cincuentenario de la Revolución los integrantes de Política compartieron la percepción de que ésta no había generado la transformación esperada y, en reacción a ello, lanzaron una propuesta de transformación que apuntaba hacia un cambio no violento. Por medio de un examen de sus contenidos, este trabajo cuestiona la idea -muy difundida- de que, debido a su carácter contestatario, Política fue el embrión de la corriente Nueva Izquierda en México. Es decir, el hecho de que en la revista dominaran los temas de la revolución cubana, el tercermundismo y la lucha contra el imperialismo, y de que se publicaran traducciones de autores emblemáticos de la Nueva Izquierda europea y estadounidense -como Jean Paul Sartre, C. Wright Mills, Carleton Beals, Claude Julien, Paul A. Baran, Paul Sweezy y K. S. Karol-, ha llevado a dar por sentado que los autores que escribían en Política pueden ser incluidos dentro de la misma categoría. Se argumenta aquí que si bien es clara la denuncia de la falta de democracia que había en México mediante una crítica innovadora de la revolución mexicana, la revista mantuvo posturas muy ortodoxas -e incluso retardatarias-frente a algunos de los acontecimientos más relevantes del periodo de la Guerra Fría. Por otra parte, a la manera del nacionalismo revolucionario, editores y colaboradores reivindicaron la figura de un "pueblo" abstracto fusionado al poder, considerado como el eje de la legitimidad revolucionaria. Finalmente, la propuesta contracultural fue inexistente.

El trabajo plantea que habrá que esperar algunos años para que aparezcan una serie de revistas representativas de una 
izquierda vanguardista, entendida a la vez como un movimiento político y contracultural, con un posicionamiento crítico frente al marxismo ortodoxo. Se trata de La Cultura en México, el suplemento de la revista Siempre! durante los años en que tuvo una dirección colectiva encabezada por Carlos Monsiváis (1972-1978); Cuadernos Políticos, desde mediados de los setenta hasta el inicio de los noventa; Nexos y El Buscón en los ochenta, y finalmente El Machete (1980-1981) y La Jornada Semanal (1989-1995), dos publicaciones dirigidas por Roger Bartra. En ocasiones de corta duración o todavía ligadas al Partido Comunista, la aparición de estas revistas hizo patente la transformación de una parte de la izquierda mexicana hacia planteamientos que rompían con el nacionalismo cardenista y hacia una crítica incisiva en los terrenos de lo cultural y lo social.

La estructura del ensayo es la siguiente. Se presentan primero las grandes líneas del debate actual acerca de la Nueva Izquierda. Se ofrece después un panorama del contexto en el cual aparece Política al inicio de los años sesenta. El siguiente apartado examina el vínculo entre los intelectuales que pertenecieron a la generación de Medio Siglo y la revolución cubana, así como la orientación de su crítica a la revolución mexicana. Los temas del tercermundismo y del antiimperialismo son abordados en el apartado quinto. ${ }^{11}$ Por último, se presentan algunas conclusiones. Los límites cronológicos del ensayo están dados por el inicio de la publicación de Política en mayo de 1960 y la realización de la Conferencia Latinoamericana por la Soberanía Nacional, la Emancipación Económica y la Paz, y el Movimiento de Liberación Nacional en 1962.

${ }^{11}$ La revolución cubana, el tercermundismo y la crítica del imperialismo fueron tres ejes temáticos que predominaron durante los primeros años en que la revista se publicó. Esto no implica que no se debatieran otros temas relevantes -como por ejemplo la relación con Estados Unidos y con otros países de América Latina-, que los límites de este artículo no permiten desarrollar. 


\section{LA NUEVA IZQUIERDA}

En un estudio acerca del periodo de la posguerra, el historiador británico Tony Judt escribió que la intelectualidad comunista que atravesó por la experiencia de la segunda guerra mundial, el nazismo y el periodo estalinista en Europa, adoptó posturas ortodoxas derivadas de una línea de partido que impuso una camisa de fuerza al pensamiento crítico, estableciendo una distinción tajante entre lo "correcto" y lo "incorrecto" en todas las dimensiones de la vida política, artística e intelectual. En reacción a lo anterior, durante los años cincuenta apareció una nueva corriente de la izquierda europea que reformuló la ortodoxia marxista a partir de una relectura de la obra de Marx. Esta corriente se apoyó en el estudio del marxismo para, desde ahí, "echar por la borda el pesado y mancillado bagaje de la izquierda tradicional europea". ${ }^{12}$ Tomemos como ejemplo el caso de un autor como Claude Lefort, que muy tempranamente -al abandonar su militancia en el partido trotskista-comenzó a aplicar las categorías utilizadas por el análisis marxista para hacer la crítica de la sociedad burguesa, al estudio del movimiento obrero y del fenómeno burocrático en la URSS. ${ }^{13}$ Los grupos que animaron la discusión acerca del totalitarismo en Francia surgieron de círculos intelectuales que provenían de una izquierda crítica vinculada a la disidencia de Europa del Este exiliada en ese

12 JudT, Postguerra. Una historia de Europa desde 1945, p. 587.

13 Lefort señaló retrospectivamente que su experiencia militante en el trotskismo fue el punto de partida de su crítica al fenómeno totalitario. La militancia, escribe, lo llevó a "escrutar el extraño movimiento a partir del cual un grupo [aún minoritario y sin capacidad de acción] reintroducía en su seno las reglas, las prácticas, las relaciones interpersonales propias de las organizaciones que decía combatir, desarrollando el mismo tipo de tejido social, cultivando los principios de la división, la parcialización de todos los ámbitos de actividad, la segregación de la información, haciendo de su sobrevivencia un fin, y dotándose de una naturaleza opaca y cerrada a la reflexión". LEFORT, "Le nouveau et l'attrait de la répétition", pp. 360-361. 
país. Entre 1948 y 1967, Claude Lefort y Cornelius Castoriadis crearon la revista Socialisme ou Barbarie; y en las dos décadas siguientes, en compañía de Marcel Gauchet, Krystof Pomian, Miguel Abensour y Pierre Clastres, animaron revistas como Textures y Libre, que tuvieron un papel clave en el debate político antitotalitario. ${ }^{14} \mathrm{El}$ grupo reunido en torno de Socialisme ou Barbarie cuestionó las ideas de Sartre y de los intelectuales que mantuvieron posturas prosoviéticas después del informe Jruschov. ${ }^{15}$ Sin embargo, a nivel internacional, Sartre y su grupo fueron reconocidos como los representantes de la Nueva Izquierda francesa, que dieron difusión a sus ideas por medio de la revista Les Temps Modernes, así como de los semanarios L'Observateur y L'Express.

A partir de una indagación acerca de la Nueva Izquierda estadounidense -definida por Van Gosse como un conjunto de experiencias políticas que se radicalizaron en reacción a la Guerra Fría, y que entre 1960 y 1980 atravesaron por sucesivas etapas- ${ }^{16}$ en años recientes la historiografía estadounidense ha examinado el tema de la transformación de la izquierda ortodoxa en América Latina y el surgimiento de una corriente innovadora que se conoció como la Nueva Izquierda al inicio de los años sesenta. En un artículo publicado en 2008, Eric Zolov constató la ausencia de una definición rigurosa del concepto de Nueva Izquierda en el contexto latinoamericano, proponiéndose

${ }^{14}$ En paralelo, la Universidad de Nanterre (París X) albergó a un grupo de politólogos encabezados por Annie Kriegel, Alain Courtois y Marc Lazar, que editaron la revista Communisme. A partir de 1976, la revista Esprit reunió a otro grupo crítico animado por Paul Thibaud y Olivier Mongin. A la par existió otro núcleo de intelectuales ligados a corrientes de derecha liberal (Raymond Aron, Alain Besançon) y socialdemócrata (Pierre Hassner), que desarrollaron también una reflexión crítica acerca del totalitarismo.

15 Véase LeForT, “La méthode des intellectuels progressistes”. Este artículo fue publicado en Socialisme ou Barbarie en 1958.

16 Gosse, "A Movement of Movements: The Definition and Periodization of the New Left”, p. 279. 
ampliar los límites de los estudios existentes a partir de un análisis del caso mexicano. Retomando la perspectiva de Van Gosse, Zolov planteó que dicho "movimiento de movimientos" estuvo marcado por dos vertientes: una vertiente política vinculada a una vanguardia revolucionaria que reivindicaba la violencia (las guerrillas) y una vertiente contracultural no violenta referida a una transformación de las sensibilidades y de los códigos sociales tradicionales. ${ }^{17} \mathrm{La}$ vertiente contracultural -que se manifestó en los terrenos del arte (el cine, la literatura, el teatro, la música) y la sexualidad (los movimientos feministas)- es para este autor un rasgo distintivo de una Nueva Izquierda latinoamericana, opuesta tanto al poder del Estado como a las normas patriarcales dominantes. Entendida desde esta perspectiva, a la vez política y contracultural, Zolov ve en la Nueva Izquierda un movimiento "transnacional" que se desarrolló simultáneamente en diversos países y que compartió algunas referencias de base, como por ejemplo el apoyo a la revolución cubana, la condena de la Guerra de Vietnam y la aspiración socialista, fuera ésta marxista-leninista o demócrata cristiana. ${ }^{18}$ Destaca también que la sensibilidad contestataria e "irreverente" que caracterizó a la Nueva Izquierda latinoamericana cobró fuerza sobre todo en la clase media. Su análisis no contempla el tema de la crítica de la ortodoxia comunista desde el marxismo, que es un elemento central para entender el surgimiento de una nueva corriente de izquierda en el contexto europeo.

Jóvenes historiadores de la Guerra Fría en América Latina han dado continuidad a las interpretaciones de Van Gosse y de Eric Zolov acerca de la Nueva Izquierda. En un libro sobre la historia de las relaciones entre México, Cuba y los Estados Unidos durante la Guerra Fría, Renata Keller propone la existencia

17 Zolov, "Expanding our Conceptual Horizons: The Shift from an Old to a New Left in Latin America", p. 51. Del mismo autor, véase "Latin America in the Global Sixties".

18 Zolov, "Expanding our Conceptual Horizons", p. 55. 
de una interconexión estrecha entre la política interna y los asuntos internacionales, de manera que las tensiones internas en torno de la legitimidad y el legado de la revolución mexicana habrían determinado el papel de México durante la Guerra Fría a nivel hemisférico.$^{19} \mathrm{En}$ el contexto de esta interpretación identifica el surgimiento de una Nueva Izquierda, definida por Van Gosse como un "movimiento de movimientos", con una fuerte impronta contracultural, que se desarrolló a nivel transnacional y que estuvo muy influida por la revolución cubana. ${ }^{20}$

Sin desmerecer la importancia de la vertiente contracultural señalada por Zolov, Jeffrey Gould propone un análisis de la Nueva Izquierda latinoamericana en el cual lo político ocupa un lugar prioritario. ${ }^{21}$ La Nueva Izquierda, escribe Gould, "politizó todos los aspectos de la vida social y cultural, y su crítica hacia

19 Keller, Mexico's Cold War, pp. 5-6.

20 Keller, Mexico's Cold War, p. 51.

21 'Following Eric Zolov and others, 'New Left' here refers to participants in a wide variety of protest movements, many of whom did not fully endorse the ideological and tactical principles of the revolutionary left, which was often committed to urban and rural guerrilla warfare. The 'New Left' did share with the revolutionaries an opposition to capitalism and to the leadership of the pro-Communist left. Up until 1968, the Latin American 'traditional' left fought for a 'democratic-bourgeois' revolution, in alliance with a progressive bourgeoisie in opposition to feudal and imperial forces. An agrarian reform would help to create the necessary domestic market for manufactured goods and lead to the development of an autonomous, capitalist society. During the 1960s, the Communist parties and their allies had limited electoral significance outside Chile [...]. The Communist left had a major presence, however, in the labor movements of Brazil, Chile, and Uruguay, and to a lesser degree in Peru, Colombia, and Venezuela. The New Left rejected the 'reformism' of both the Communist parties and the labor movements. Inspired by the Cuban Revolution, activists placed socialist revolution on the agenda and argued that because of the imperialist counterinsurgency unleashed since the Cuban Revolution, there was no peaceful, reformist road to socialism. The New Left also opposed the Soviet Union both as a world actor and as a model, without fully articulating a critique." Gould, "Solidarity under Siege: The Latin American Left, 1968", pp. 350-351. 
la política parlamentaria no debe confundirse con un rechazo o con un debilitamiento de su percepción acerca de la política o de la conciencia política". ${ }^{22}$ Añade que si bien la Nueva Izquierda latinoamericana compartió algunos rasgos con las corrientes europea y estadounidense, su evolución estuvo determinada por la represión de la cual fue objeto. Esto último lo lleva a enfatizar la importancia de los partidos comunistas latinoamericanos durante este periodo, en la medida en que sus encuentros y desencuentros con la Nueva Izquierda tuvieron siempre como telón un mismo contexto de violencia y represión.

El tema de la reformulación del marxismo ortodoxo en el contexto intelectual latinoamericano ha sido abordado por Patrick Iber en un libro reciente acerca del Comité por la Paz y la Libertad en América Latina. Este autor observa que la nueva intelectualidad que apareció en América Latina durante los años sesenta desplazó el debate que en los años cincuenta estuvo centrado en el conflicto Este-Oeste, hacia una discusión acerca de la aceptación o el rechazo de la vía cubana y de su influencia intelectual, política y militar sobre los países en vías de desarrollo. ${ }^{23}$

En México, el término Nueva Izquierda comenzó a circular al inicio de los años sesenta. La revista Nueva Izquierda fue una publicación de efímera duración -solo se publicaron dos números, que aparecieron entre 1960 y 1961-, casi contemporánea de Política. Al frente de ella estuvo un grupo de estudiantes de ciencias sociales de la UnAm: Rolando Cordera, Gabriel Careaga, Antonio Delhumeau, Octavio Rodríguez Araujo, Roberto Escudero, Carlos Monsiváis, Raúl Olmedo, Ricardo Valero y Margarita Suzán. Algunos de ellos colaboraron esporádicamente en Política, como fue el caso de Carlos Monsiváis. ${ }^{24}$ Por su parte, Jaime Pensado considera que la revista El Espectador

22 Gould, "Solidarity under Siege", p. 349.

23 Iber, Neither Peace Nor Freedom, pp. 117-118.

24 Rodríguez y Concheiro, "Nueva izquierda: una revista estudiantil”. 
(1959-1960) fue "la voz de la nueva izquierda en México", por haber establecido una distancia frente al comunismo y el marxismo ortodoxos, alentando al mismo tiempo la formación de espacios democráticos. ${ }^{25}$

\section{LA REVISTA POLÍTICA}

La década de los sesenta en México estuvo marcada por la efervescencia política. Es un periodo en el que Barry Carr identifica la aparición de un amplio espectro de "tendencias, movimientos y organizaciones unidos en torno al objetivo central de democratizar la sociedad mexicana". ${ }^{26} \mathrm{Al}$ lado del proletariado industrial, surgieron nuevos actores revolucionarios: los marginados urbanos, los ejidatarios, los campesinos sin tierra, los jóvenes, los estudiantes, los trabajadores del sector estatal y los cristianos radicalizados, que integraron una multiplicidad de "frentes" amplios en todo el país. ${ }^{27}$ En este contexto, escribe Jaime Pensado, los estudiantes de la UNAM comenzaron a desempeñar un papel importante; teniendo como antecedente inmediato los movimientos estudiantiles de 1956 y de 1958, animaron nuevos espacios de crítica política y de contracultura que permitieron recuperar el lenguaje y los códigos que comenzaban a circular en el ámbito internacional..$^{28}$

Entre los nuevos actores políticos destacó la figura del intelectual comprometido con las causas antiimperialista y tercermundista. A los intelectuales, escribió Carlos Fuentes en un ensayo en el que analizó retrospectivamente estos años, tocaba analizar la "realidad actual de México" y ofrecer "una tipificación histórico-crítica de la revolución mexicana, una caracterización presente de los grupos en el poder, de los grupos de

25 Pensado, Rebel Mexico, p. 152.

26 CARr, “El nacimiento de una nueva izquierda, 1960-1975”, pp. 229-230.

27 CARr, “El nacimiento de una nueva izquierda, 1960-1975”, pp. 229-230.

28 Pensado, Rebel Mexico, p. 151. 
presión, de las clases sociales, de las relaciones exteriores, de la forma concreta en que actúan el capitalismo y el imperialismo en México". En este texto, Fuentes subraya la importancia del científico social, que daría continuidad a la tarea crítica que hasta entonces habían "realizado parcialmente la literatura y el arte". ${ }^{29}$

La revista Política constituyó un espacio abierto a la difusión de las ideas de estos escritores, artistas y científicos sociales que denunciaban la falta de democracia, el fracaso de la revolución mexicana como proyecto y el anquilosamiento de las instituciones. Los fundadores de la revista fueron Manuel Marcué Pardiñas, ingeniero agrícola y periodista ligado a Problemas Agrícolas e Industriales de México, y Jorge Carrión, economista y autor del libro Mito y magia del mexicano. ${ }^{30}$ Entre los colaboradores más conocidos de la revista se encontraban Alonso Aguilar, Narciso Bassols Batalla, Fernando Benítez, Enrique Cabrera, Fernando Carmona, José de la Colina, Víctor Flores Olea, Carlos Fuentes, Enrique González Pedrero, Alejandro Gómez Arias, Eli de Gortari, Renato Leduc, Vicente Lombardo Toledano, Francisco López Cámara, Germán List Azurbide, Salvador Novo, David Alfaro Siqueiros, Víctor Rico Galán y José Santos Valdés. ${ }^{31}$ La publicación de Política fue posible gracias al apoyo de la revista Problemas Agrícolas e Industriales de México (1946-1959), "cuya finalidad era reproducir y difundir documentos oficiales del gobierno mexicano y apoyar sus programas de comunicación social [lo cual] expone cierto vínculo

\footnotetext{
${ }^{29}$ Fuentes, “Radiografía de una década, 1953-1963”, p. 86.

30 Marta Quesada sostiene que Jorge Carrión "se separó de Política entre marzo y diciembre de 1961, para regresar a ella a inicios de 1962, ya sin el cargo de director, aunque siguió elaborando los editoriales y participando en la sección Panorama Nacional, que Marcué consideraba la más importante de la revista”. Marta Quesada, "Jorge Carrión y la revista Política”, p. 2.

${ }^{31}$ La lista de los redactores y colaboradores de la revista en sus primeros tiempos apareció en el primer número de la revista. Política (1으 mayo 1960), año I, num. 1.
} 
entre sectores de la izquierda y el ámbito gubernamental”, afirma Juan Rafael Reynaga Mejía en uno de los pocos estudios que se han concentrado en el análisis de esta publicación. ${ }^{32} \mathrm{La}$ impresión quincenal se realizaba en los Talleres Gráficos de la Nación con un tiraje inicial de 15000 ejemplares.

La imagen -fotografía y caricatura- tuvo un papel importante. Las portadas fueron siempre una fotografía o un montaje de ellas; en las páginas internas, los reportajes y artículos generalmente estuvieron ilustrados. ${ }^{33}$ Los servicios fotográficos provinieron del estudio de los Hermanos Mayo, de la agencia Prensa Latina, así como de los encargos que se hicieron a Enrique Bordes Mangel, Rodrigo Moya y Rodrigo Mújica para cubrir determinados actos o reportajes. ${ }^{34}$ Las fotografías no aparecían firmadas, a diferencia de las caricaturas, que corrieron

32 Reynaga Mejía, La Revolución cubana en México a través de la revista Política, p. 33.

33 Sin embargo, escribe Rodrigo Moya, a mediados del siglo xx el fotorreportaje en México todavía se encontraba en pañales: "Se le llamaba 'reportaje' a un conjunto afortunado de fotos sobre un mismo tema, tomadas generalmente en un solo día, o sobre una acción que sucedía vertiginosamente. No había un proyecto previo presentado por el fotógrafo, por un reportero o la dirección de la revista. Tampoco había patrocinio para movilizaciones a lugares lejanos, facilidades de trabajo, material suficiente, viáticos, tiempo, salario asegurado. Hubo notables excepciones, pero en general el reportaje carecía de profundidad y se improvisaba sobre la mesa de redacción cuando un buen conjunto de fotos merecía el agregado de un redactor, o en mi caso, con frecuencia, el de mis propios textos. Los mejores reportajes de ese tiempo fueron iniciativas personales de fotógrafos independientes, que escasamente podrían recuperar el tiempo y los materiales invertidos". Moya, "Con los ojos bien abiertos. El reportaje", p. 109.

${ }^{34}$ La colaboración estrecha entre la agencia cubana de noticias Prensa Latina y la revista Política me fue confirmada por Rodrigo Moya, uno de los reporteros gráficos más importantes de la época y que estuvo cerca de los editores de la revista. Además de en Política, Moya colaboró en Impacto, El Espectador, Continente, Siempre! y Sucesos para todos. Conversación con Rodrigo Moya, Cuernavaca, noviembre de 2017. 
a cargo de los mexicanos Rius, Abel Quezada y R. Freire; del cubano Chago, el francés Bosh, el inglés Vicky, los estadounidenses Bartolí y R. Brown, y del ruso Dtsinovski. ${ }^{35}$

El título de la revista se desprendió de lo que se presentó como su objetivo: "Devolver a la palabra política su prestigio y su connotación y valor social, conectarla con las actividades superiores de la práctica y del pensamiento, extender su dominio a todos los territorios económicos, sociales y culturales que convienen con su esencia humanística". ${ }^{36}$ El editorial que abrió el primer número subrayaba también la importancia que se daría a la relación entre la problemática nacional y los acontecimientos internacionales: "Política examinará la vida nacional en su complejidad interior y en su relación internacional, con la finalidad de mostrar la verdad en su movible naturaleza conforme al principio de la continua evolución social". ${ }^{37}$ Uno de los rasgos característicos de la revista fue, en efecto, establecer un vínculo entre México y el mundo, entre el análisis de la política interna y la reflexión acerca de los grandes acontecimientos que estaban teniendo lugar (la revolución cubana), así como de los movimientos sociales que habían cobrado fuerza a nivel mundial (el tercermundismo y el antiimperialismo). Su estructura misma revela el equilibrio y la interconexión que se buscó alcanzar entre los temas nacionales y la problemática internacional, así como entre la reflexión política y la crítica cultural. Al Correo de los lectores y el Editorial, seguían las secciones de Panorama Nacional, Estados y Territorios, Nuestro Continente, El Mundo, Economía, Cultura y Ciencia.

Independientemente de su pertenencia a un mismo partido -al PRI, al PC o al PPS-, antes de colaborar en Política una parte de los intelectuales que participaron en ella-Carlos Fuentes, Víctor

${ }^{35}$ Reynaga Mejía, La Revolución cubana en México a través de la revista Política, p. 33.

${ }^{36}$ Editorial s/f, "Nuestro compromiso", p. 2.

37 Editorial s/f, "Nuestro compromiso", p. 2. 
Flores Olea, Enrique González Pedrero, Francisco López Cámara- estudiaron en la Facultad de Derecho e incursionaron en revistas literarias como Medio Siglo y la Revista Mexicana de Literatura. El clima intelectual que reinaba en México al inicio de los sesenta favoreció la formación de círculos que emprendieron un análisis crítico de la realidad mexicana y que manifestaron un apoyo abierto a la revolución cubana; entre ellos, el Círculo de Estudios Mexicanos A. C., animado por Enrique Cabrera, Eli de Gortari, Jorge Carrión y Alonso Aguilar. ${ }^{38}$ Por otra parte, es posible identificar actividades muy puntuales que también dejaron una huella. Guillermo Hurtado señala, por ejemplo, que un número significativo de los intelectuales que entre 1960 y 1967 integraron la revista Política, y que entre 1959 y 1960 habían colaborado en El Espectador-Víctor Flores Olea, Carlos Fuentes, Enrique González Pedrero, Francisco López Cámara, Jaime García Terrés, José Luís Martínez, Jorge Portilla, Emilio Uranga y Leopoldo Zea-, participaron en una encuesta crítica acerca de la revolución mexicana que se publicó en el primer número de 1959 de Cuadernos Americanos. ${ }^{39}$

A principios de 1961 Enrique González Pedrero, miembro del PRI, publicó en la revista un duro cuestionamiento al partido en el poder: "los tiempos han cambiado, el antiguo aparato creado para otras épocas ya no funciona". Descartaba la posibilidad de que el PRI pudiera renovarse por considerar que la transformación de México se desprendería de un amplio movimiento de izquierda vinculado al "pueblo":

[la revolución institucional] no puede renovarse so pena de autoliquidarse. ¿Por qué? Porque para renovar al PRI hace falta la democracia interna, desde abajo, desde los militantes, y la democracia

38 "Manifiesto del Círculo de Estudios Mexicanos A. C. a favor de Cuba." 39 Hurtado, "Un antecedente de El Espectador". 
interna pulverizaría a las tres columnas -las tres centrales- que se fundan precisamente en los métodos que ahora ellos (los jóvenes priistas) han sufrido en carne propia. Y esos métodos no se superan en función de las amenazas, los chantajes y “cartas abiertas” con que se han tapizado los periódicos en estos días. La única manera de superarlos, de renovar a México, es yendo hacia el pueblo. Solamente entonces serán posibles las modificaciones que el mismo pueblo está pidiendo a gritos. ${ }^{40}$

Se trata de una crítica innovadora por haber sido formulada desde el interior del partido oficial y por plantear que la única opción para transformar al país era crear una nueva coalición de izquierda. Al mismo tiempo, González Pedrero apelaba a una entidad totalizadora y sin diferenciación interna -el "pueblo"de la cual los intelectuales comprometidos aspiraban a convertirse en portavoz, cuando una buena parte de ellos se encontraba ligada al partido y al gobierno que denunciaban. De manera que Política nació marcada por la contradicción de estar sostenida por el gobierno y de llamar al cambio mediante la formación de un movimiento amplio de oposición. Para complicar más el panorama habría que añadir el hecho, señalado por Renata Keller, de que el gobierno de López Mateos apoyó oficialmente la causa de la revolución cubana, pero al mismo tiempo reprimió las manifestaciones de apoyo a Cuba y colaboró secretamente con las tareas estadounidenses de espionaje a Castro; las oficinas de la ciA en México mantuvieron, en efecto, vínculos estrechos con la Dirección Federal de Seguridad. ${ }^{41}$ Esto explica los altibajos de la relación entre el régimen de López Mateos y Política, así como el rechazo de Díaz Ordaz a la revista - percibida como amenazante por su orientación ideológica- y su cierre en 1967 a

40 González Pedrero, “La crisis llega al Pri”, p. 21.

41 Keller, Mexico's Cold War, p. 70. 
causa de las restricciones impuestas por la empresa comercializadora oficial de papel PIPSA. ${ }^{42}$

\section{LA GENERACIÓN DE MEDIO SIGLO Y LA REVOLUCIÓN CUBANA}

Los intelectuales y periodistas que configuraron el núcleo central de Política durante los dos primeros años en que fue publicada pertenecieron en su mayor parte a la Generación de Medio Siglo nacida entre 1921 y 1935, que según Enrique Krauze se caracterizó por un sentido de compromiso social y un espíritu crítico arraigados en el cardenismo. En medio de las celebraciones del cincuentenario, compartieron una nueva forma de cuestionamiento a la revolución mexicana:

Políticamente, su blanco principal es el hieratismo de los Cachorros de la Revolución. No analizan, señalan. Exhiben la ostentación de la burguesía, la corrupción administrativa, la enajenación de los medios de comunicación, la mentira de la prensa, el charrismo, la farsa del discurso oficial, el saqueo alemanista, el desarrollismo sin justicia social. Su crítica nace más de un temple inconforme que de una dolorosa sensación de pérdida como es el caso de la crítica que por esos años despliegan los hombres del 15. El mayor

${ }^{42}$ Además del control del papel, desde fines de 1960 los editores de la revista denunciaron diversas formas de presión por parte del gobierno. Véase MARcué Pardiñas y CARrión, "Problemas con PIPSA". John King cita el fragmento de un texto de Huberto Bátiz en donde se especifica cuáles fueron estas formas de presión, a raíz del apoyo irrestricto a Cuba y de la cercanía con el MLN. En palabras de Bátiz: "Vendrían tiempos difíciles para Manuel [Marcué Pardiñas] cuando Política empezó a molestar al gobierno; le cortaban la luz [...] rompían los guaruras un vidrio de la imprenta, introducían una manguera gruesa, y por ahí bombeaban talco en grandes cantidades hasta que se coagulaba toda la grasa de las máquinas y las paralizaba". Citado en KING, Plural en la cultura literaria y política mexicana, p. 58. 
exponente de esta actitud es quizá Carlos Fuentes. Un poema representativo: "El presidente” de Jorge Hernández Campos. ${ }^{43}$

A fines de los años cincuenta esta crítica se fortalece y amplía con el entusiasmo suscitado por la revolución cubana. Aunque no menciona a la revista, la interpretación de Krauze acerca de la Generación de Medio Siglo coincide con el perfil de los jóvenes intelectuales agrupados en Política al inicio de los años sesenta:

[...] mientras el gobierno celebra los cincuenta años de Revolución, con la perspectiva de Cuba algunos intelectuales jóvenes sostienen que México vive apenas una seudorrevolución. Otros ven en la defensa de la revolución cubana la forma mejor de defender a la auténtica revolución mexicana, de ahí su acercamiento a Lázaro Cárdenas. La década de los sesenta presencia una continua radicalización del grupo (Flores Olea, González Pedrero, Villoro, López Cámara) hacia la izquierda, al grado en que algunos intentan, sin éxito, constituir una agrupación política independiente: el M.L.N. [...] Conciben su papel ligado orgánicamente a los movimientos populares. Interpretan que su deber es expresar con claridad y pasión, las necesidades del pueblo. ${ }^{44}$

Refiriéndose al caso de Francia en los años sesenta, Jeannine Verdès-Leroux identificó tres grandes olas de entusiasmo a favor de la revolución cubana. La primera coincidió con la instauración del nuevo régimen y su expresión más lograda fue el reportaje de Jean-Paul Sartre «Ouragan sur le sucre», publicado en France Soir y editado en Cuba en 1960. La segunda ola se desencadenó en febrero de 1965, con el llamado emitido al bloque socialista por Ernesto Guevara desde Argel para que apoyara activamente a los países coloniales que luchaban por su

43 KraUze, “Cuatro estaciones de la cultura mexicana”, p. 35.

44 Krauze, “Cuatro estaciones de la cultura mexicana”, p. 36. 
liberación; este llamado se convirtiría en el rasgo distintivo del revolucionarismo a la vez teórico y práctico de Guevara. Por último, el régimen castrista generó una tercera ola de entusiasmo con la organización del Salón de Mayo en La Habana en agosto de 1967; y, mas aún, con el Congreso Cultural que reunió en La Habana a 500 intelectuales de 70 países en enero de $1968 .{ }^{45}$

En América Latina la revolución cubana despertó optimismo entre los intelectuales de izquierda, ante quienes aparecía -escribe John King- como "un movimiento nacionalista y antiimperialista ejemplar, que parecía exigir un compromiso intelectual y práctico ante la promesa utópica de reunir las vanguardias artísticas y políticas". ${ }^{46}$ De ahí que, al igual que en Europa y Estados Unidos, la primera ola de entusiasmo procastrista impactara al grupo de jóvenes reunidos en Política. La salida del primer número el 1o de mayo de 1960 coincidió con la celebración del Encuentro de Solidaridad con Cuba convocado en La Habana para celebrar el Día del Trabajo. La delegación mexicana a dicho Encuentro estuvo integrada por varios miembros de la revista. ${ }^{47}$ Uno de ellos, Carlos Fuentes, describió así el ambiente de la celebración, destacando el momento en que Fidel Castro subió a la tribuna: ${ }^{48}$

\footnotetext{
45 Verdès-Leroux, La lune et le caudillo, pp. 12-13.

${ }^{46} \mathrm{KING}$, Plural en la cultura literaria y política mexicana, p. 69.

${ }^{47}$ La delegación estuvo integrada por Alonso Aguilar, Fernando Benítez, Enrique Cabrera, Fernando Carmona, Jorge Carrión, Víctor Flores Olea, Carlos Fuentes, Pablo González Casanova, Vicente Lombardo Toledano, Manuel Marcué Pardiñas, David Alfaro Siqueiros. Reynaga Mejía, La Revolución cubana en México a través de la revista Política, p. 39.

${ }^{48}$ Algunas décadas más tarde, Carlos Fuentes matizó el entusiasmo que la revolución cubana había suscitado en su generación: "No defendimos nunca, en sentido estricto, a Cuba o a Chile, a Nicaragua, Guatemala o El Salvador: defendimos, al defender el derecho, a México”. Asimismo, relativiza la manera en que sus contemporáneos reaccionaron ante los problemas de su tiempo: "nos tocó vivir una época tan difícil como la que conformaron nuestros padres, pero mucho más estéril: las décadas de la guerra fría y su división hermética en esferas irreconciliables, su comodidad maniquea para situar a los buenos y a los
} 
Desde la tierra se levanta un vuelo de palomas. Fidel Castro está en la tribuna. La plaza, de extremo a extremo, se ha colmado [....] Ahora todo se detiene. Una comunicación poderosa, eléctrica, levantada, se establece entre el pueblo y su dirigente. Hay un minuto en el que Fidel parece estar hablando en silencio con ese millón y medio de cubanos, y ellos con él. No se trata, sin embargo, de una mística: se trata de una razón. Lo irracional -dicen todos los rostros, todas las voces de Cuba- es lo que se ha dejado atrás, lo que ese hombre y sus doce compañeros del Granma destruyeron con el apoyo del pueblo. ${ }^{49}$

Para Fuentes, la revolución cubana no cabía en el modelo democrático clásico, ya que la "comunicación poderosa, eléctrica, levantada” que se establecía "entre el pueblo y su dirigente” en una asamblea como la del 1o de mayo fungía como sustituto del sufragio. ${ }^{50}$ En palabras del escritor, "las voces del millón y medio de cubanos son una sola voz: Elecciones, ¿para qué? ¡Ya votamos por Fidel! Lo dice con las armas en la mano". ${ }^{51}$ Asimismo, la Revolución no podía garantizar las libertades debido a que "no hay libertad para quienes no la merecen: los traidores, los mercenarios, los latifundistas, los explotadores, los privilegiados de la dictadura". ${ }^{2}$ En este primer momento de la revolución cubana, la izquierda nacionalista mexicana mitificó a Fidel como un dirigente que, además de haber logrado imponerse al imperialismo, poseía la capacidad de establecer

malos, y su sacrificio de la diversidad política, social y sobre todo cultural, de los pueblos, en aras de dos ideologías heladas y excluyentes de todo lo que no fuesen ellas, incluyendo lo que éramos y somos, nosotros". Fuentes, "Regreso al hogar. Mi casa veracruzana”, pp. 194-195.

49 Fuentes, "Primero de mayo en La Habana”, p. 46.

50 Acerca de la inoperancia del sufragio en la Cuba castrista véase BENítez, La batalla de Cuba, p. 118.

51 Fuentes, "Primero de mayo en La Habana”, p. 47 (las cursivas aparecen en el texto).

52 Fuentes, "Primero de mayo en La Habana”, p. 47. 
una comunicación poderosa y directa con el "pueblo", de la cual se desprendía la fascinación que ejercía como líder. El escritor Juan José Arreola llegaría a preguntarse si esta capacidad de comunicación provenía de que Fidel había surgido cuando el pueblo estuvo listo para ello, o si el "caudillo" fue "obra del pueblo cubano". 53

¿Qué tipo de régimen encabezaba entonces Fidel Castro? Fernando Benítez definió a Fidel como un "revolucionario nacionalista" -categoría que también podía aplicarse al régimen mexicano-que no buscaba instaurar ni el comunismo ni una dictadura y que se caracterizaba por haber desplegado "un tipo de heroísmo que por desgracia no se da frecuentemente en América Latina". ${ }^{54}$ Víctor Flores Olea planteó que la democracia cubana era "esencialmente dinámica", es decir, un sistema en el cual "las categorías políticas aplicables en las épocas de normalidad no revolucionaria, dejan de tener vigencia" ${ }^{55}$ Además de que Cuba atravesaba por un momento de excepción en que el régimen revolucionario había tenido que asumir todos los poderes para prevenir un golpe contrarrevolucionario, el sociólogo consideraba que el modelo político cubano era incompatible con los mecanismos democráticos clásicos. En palabras de Flores Olea:

La democracia cubana es una democracia directa, plebiscitaria, concreta, diría más exactamente; en la cual, pueblo y Gobierno están perfectamente compenetrados en las exigencias y los intereses del uno, y de las dificultades y necesidades del otro. El Gobierno es el pueblo en acción; el pueblo, el «espíritu» de la política revolucionaria del Gobierno. Para lograrlo, en Cuba se ha implantado un diálogo permanente, abierto, entre los dirigentes y el pueblo... [del] examen de las cuestiones nacionales en las plazas públicas,

53 Arreola, "Por qué estoy con Cuba”, p. 34.

54 Benítez, “Cuba: la prueba de fuego para Estados Unidos o la parábola de David y Goliat”, p. 42.

55 Flores Olea, “Cuba, una democracia concreta”, p. 10. 
de esta coincidencia de objetivos y de esta perfecta unidad, nace la acción revolucionaria como la única acción que exige todo el pueblo de Cuba. ${ }^{56}$

Flores Olea afirmaba que esta "perfecta unidad” que se había establecido entre “pueblo y Gobierno” justificaba incluso la represión. Por ello, después de haber prestado oídos a la voz del “campesino, del obrero, del estudiante”, el régimen revolucionario había decidido eliminar a "los cuadros intermedios que normalmente vemos funcionar en las democracias representativas", convirtiendo este hecho en "su característica fundamental". ${ }^{7}$ Fernando Benítez daba incluso un paso más allá. No solo corroboraba la ausencia de libertades, ${ }^{58}$ sino que en su libro La batalla de Cuba justificaba las ejecuciones perpetradas en nombre de la Revolución. Su argumento era que la prensa no hablaba de la sangre derramada por Batista, en tanto que la "sangre derramada por los hombres de Fidel Castro [...] ha merecido una repulsa universal. Los periódicos se impregnaron con la pólvora de las ejecuciones”. “¿Por qué sentaron a Cuba en el banquillo de los acusados?”, se preguntaba al emprender un primer viaje a la isla en enero de 1959. ${ }^{59}$ Durante este viaje asistió a una manifestación multitudinaria en la cual Fidel interrogaba al "pueblo"60 acerca

56 Flores Olea, “Cuba, una democracia concreta”, p. 11.

57 Flores Olea, "Cuba, una democracia concreta”, p. 11.

58 "No hay ya periódicos de oposición en Cuba. Uno a uno han ido muriendo -de muerte natural o de muerte violenta- durante el breve periodo revolucionario, y este hecho se ha esgrimido como un cargo más en contra de Fidel Castro.” Benítez, "La libertad de prensa no es la libertad de venderse al mejor postor", p. 16.

59 Benítez, La batalla de Cuba, p. 11.

60 En ocasiones, Benítez se refiere al "pueblo" -concebido como entidad abstracta- en tanto que una “masa”. Durante el desfile del 1 de mayo de 1960 observa "una masa viva, atenta a las menores señales, una masa que aguarda olvidada de su hambre. De su sed y de su fatiga. Espera a Fidel”. Benítez, La batalla de Cuba, p. 115. 
de las ejecuciones: "Yo le voy a hacer una pregunta al pueblo. Los que estén de acuerdo con la justicia que se está aplicando, los que estén de acuerdo con que los esbirros sean fusilados, que levanten la mano" ${ }^{61}$ La relación entre el caudillo y un "pueblo" que avalaba las ejecuciones -relación de la cual los intelectuales extranjeros invitados eran testigo- justificaba el giro represivo y antidemocrático que tomaba la revolución. ${ }^{62}$

El entusiasmo frente al proceso cubano dio lugar a que la crítica de la revolución mexicana tomara una nueva orientación. Desde mediados de los años cincuenta hasta mediados de los sesenta, escribe Ricardo Pozas Horcasitas, un cambio social y económico acelerado había desgastado "la representación social totalizante de la revolución mexicana, que constituyó durante décadas el horizonte cultural en donde se realizaba la acción de los dirigentes políticos, la producción intelectual y la creación de las élites artísticas de la sociedad mexicana". ${ }^{63}$ En el cincuenta aniversario de la revolución mexicana y en un momento de distanciamiento entre Política y el régimen de López Mateos a causa de las declaraciones de éste en julio de 1960 en Guaymas, en el sentido de que su gobierno era "dentro de la revolución, de extrema izquierda”, una constante en las páginas de la revista fue la crítica de la revolución mexicana a partir de los paralelismos y diferencias que existían con la cubana. Para Jorge Carrión,

${ }_{61}$ Benítez, La batalla de Cuba, p. 24.

${ }^{62}$ En paralelo, Política publicó documentos y declaraciones del gobierno cubano que desmentían el hecho de que la Revolución hubiera coartado las libertades y violentado los derechos humanos de los ciudadanos: "Frente a la criminal confabulación urdida por el imperialismo estadounidense contra Cuba, la Conferencia de los Pueblos declara que es absolutamente falso que la revolución cubana no respete los derechos humanos. Son, al contrario, los gobiernos que acusan a Cuba los que atropellan tales derechos y los que persiguen implacablemente a los ciudadanos, por razones ideológicas, políticas o sindicales". "Declaración de los Pueblos", p. 30.

${ }^{63}$ Pozas Horcasitas, "El final del horizonte: la muerte simbólica de la Revolución mexicana”, p. 36. 
esta última se había producido en un momento histórico marcado por el ocaso del capitalismo, el fortalecimiento del bloque socialista y el triunfo de los movimientos anticoloniales en Asia y África, en tanto que la revolución mexicana fue una insurrección "democrática, nacionalista y burguesa [que irrumpió] cuando el imperialismo capitalista era la fuerza hegemónica en el mundo" . ${ }^{64}$ Lo anterior, argumentaba el mismo autor, había dado lugar a que los gobiernos posrevolucionarios se aliaran con el imperialismo, apartándose del "pueblo" y traicionando lo que habían sido los orígenes del movimiento. ${ }^{65}$ Francisco López Cámara consideraba que la revolución mexicana había muerto no solo a causa del avance imperialista y del ascenso de la burguesía financiera, sino también debido a la corrupción y a la ausencia de movimientos populares. ${ }^{66}$ José Santos Valdés comparaba la crisis por la que atravesaba la revolución mexicana con la época porfiriana utilizando la metáfora de una mujer decadente y envejecida:

De unos años a esta parte, la Revolución Mexicana, tal como la pintan con toda justicia los grandes del periodismo nacional, ha engordado. Su cuello, sus muñecas, sus dedos son el asiento de lujosas joyas. Usa perfumes caros y pieles de alto precio. Come en lujosos restaurantes, baila en el Country Club, viaja por Europa, educa a sus hijos en el extranjero y es aficionada a las comidas pantagruélicas y a pagar por una copa lo que no gana un campesino en una semana de trabajo. Dejó los jacales de los pobres, olvidó la ruta de los campos y no asoma las narices por los barrios bajos de las ciudades sino de cuando en cuando, para, en espectaculares y teatrales inauguraciones, dar la apariencia de que, efectivamente, todavía es la Revolución Mexicana. El coro de los jilgueros y los

64 CARrión, “Cuba, revolución sin maracas”, p. 16.

65 Véase Flores Olea, “La revolución traicionada”, p. 36.

66 López CÁmara, “¿Está muerta la revolución mexicana?”, p. 31. 
periódicos «serios» agotan los adjetivos y los adverbios, y por todos los canales de la publicidad se desgrana un rosario interminable de cantos y loas para que el sufrido, hambriento, enfermo e ignorante Juan Pueblo sepa que la Revolución Mexicana todavía, de cuando en cuando, es la Revolución Mexicana. ${ }^{67}$

En enero de 1961, Política condenó la matanza de Chilpancingo. ${ }^{68}$ Escandalizado por este acontecimiento, poco antes de salir de la revista por estar en desacuerdo con la línea procubana, ${ }^{69}$ Emilio Uranga llamaba a la izquierda intelectual a abstenerse de colaborar con el Estado: "En nombre de esta Revolución incumplida y traicionada se le exige al intelectual que no se aproxime al Estado, que demuestre con su abstención el derecho que tiene a ser escuchado como fuerza independiente y sin compromisos". ${ }^{70}$ Algunos días antes de la represión en Chilpancingo, Carlos Fuentes había, sin embargo, abierto la puerta para que el gobierno de López Mateos corrigiera el rumbo. Las alternativas que se presentaban, decía el escritor, eran continuar escuchando a la burguesía, o bien "apoyarse en el pueblo y allanar la vía irreversible hacia la siguiente etapa de la revolución mexicana -no la conmemorativa y retórica-, sino la que empezó en 1810 y aún no termina". ${ }^{71}$

67 Santos Valdés, "Bailando con Don Porfirio", p. 28.

${ }^{68} \mathrm{El} 30$ de diciembre de 1960, el ejército reprimió violentamente un movimiento ciudadano y estudiantil contra el gobernador Raúl Caballero Aburto. El 3 de enero de 1961 se declaró la desaparición de poderes en el estado de Guerrero. Véase Fuentes, “Guerrero: ¿quién es el responsable?”; Benítez, "Como en 1910...".

${ }^{69}$ Reynaga Mejía, La Revolución cubana en México a través de la revista Política, p. 43.

70 URANGa, "Confesión necesaria”, p. 35. En este artículo, Uranga denuncia que Leopoldo Zea se hubiera "incrustado finalmente en un puesto oficial".

${ }^{71}$ FuenTes, “El pueblo puede 'saltar las trancas’”, p. 23. 
La izquierda nacionalista reunida en Política se manifestó en favor de los "movimientos progresistas de todo el mundo y, especialmente [aquellos de] América Latina”, ${ }^{72}$ argumentando que los países capitalistas occidentales se encontraban en la "fase final del imperialismo" y evolucionaban hacia el fascismo. ${ }^{73}$ Expresaba también que los países subdesarrollados se alinearían naturalmente con el socialismo, y que los movimientos de liberación en los países del Tercer Mundo conllevarían la proliferación de las revoluciones proletarias en los países capitalistas. ${ }^{74}$ Estas ideas se inscribieron en un contexto internacional en el que la URSS había dado un nuevo giro a la percepción del llamado Tercer Mundo. Las investigaciones de Vanni Pettinà muestran que la política lanzada por Khrushchev a mediados de la década de 1950 buscó revalorizar el modelo socioeconómico soviético

\footnotetext{
72 Editorial s/f, "Dos años de Política”, contraportada.

73 En las páginas de Política, Carlos Fuentes comparaba a Kennedy y a Nixon con Hitler y Mussolini: "Kennedy y Nixon nos amenazan con los mismos argumentos de fuerza con que Hitler y Mussolini amenazaron a Checoeslovaquia, Etiopía, Austria y Albania. Kennedy califica a los EU con los adjetivos de la filosofía fascista del superhombre: 'fuertes', 'visionarios'; y califica a nuestros pueblos con los que Hitler utilizaba para referirse a las 'razas inferiores': 'blandos, complacientes’. Y esa 'seguridad nacional’ de Kennedy, ¿no es idéntica al 'espacio vital' de Alemania invocado por Hitler?”. Fuentes, “Con el fascismo o con el pueblo. La hora de la definición”, pp. 10-11.

74 En un reportaje acerca de la Conferencia de Belgrado en 1961, a la cual Carlos Fuentes asistió como enviado especial de Política, el escritor anunciaba el ocaso del capitalismo a nivel mundial a partir de la revolución cubana: "La plácida dominación norteamericana de la vida económica y, a través de ella, de la vida política latinoamericana, ha sido puesta en entredicho para siempre por Fidel Castro y sus hombres. Cuba ha exorcizado el sordo fatalismo geográfico, histórico, económico, que pesaba sobre nuestros pueblos [...] la propagación del ejemplo cubano al resto de Latinoamérica, y aun a África y Asia, [provocará] tarde o temprano el derrumbe del sistema capitalista en Estados Unidos, y el de todo el mundo occidental, cada vez más integrado a la dirección del capitalismo estadounidense”. Fuentes, “De Bandung a Belgrado”, p. 16.
} 
ante el capitalista occidental mediante un acercamiento a los países en vías de desarrollo. La intención de esta estrategia era doble: "la URSS podía mostrar la superioridad de su modelo sobre el de Washington y con el tiempo mover los nuevos países hacia la adopción de modelos socialistas". ${ }^{75}$ Como parte del acercamiento a los países del Tercer Mundo, advierte el mismo autor, en 1959 la Unión soviética organizó en México una gran exposición para dar a conocer sus avances científicos y tecnológicos. Ese mismo año, la irrupción de la revolución cubana reforzó el cambio de visión que Khrushchev estaba tratando de imprimir. Todo ello influyó en la creación de instituciones académicas como el Instituto de América Latina de la Academia de Ciencias de la URSS en 1961, "un centro de análisis y de estudio sobre el continente cuyas investigaciones habrían de guiar la elaboración y puesta en marcha de la política soviética hacia el continent" ${ }^{76}$

No es pues de extrañar que Política manifestara en sus páginas una gran admiración por el proyecto soviético, los avances de su economía, sus logros científicos (en particular los primeros viajes espaciales) ${ }^{77}$ y su cultura. Los intercambios entre México y la Unión Soviética fueron objeto de una amplia difusión; entre ellos, la muestra de arte que el gobierno mexicano envió a Moscú en $1960 .{ }^{78}$ En materia política, Política evitó hacer un cuestionamiento al estalinismo. Si bien algunos autores hicieron alusión a la crítica que Khrushchev hizo de este periodo, nunca se menciona su papel activo en la represión de la revolución húngara de 1956: "a diferencia de Stalin, argumentaba Flores Olea, Jruschov [sic] no 'maniobra' con la guerra, sino con la

\footnotetext{
75 Pettiná, “¡Bienvenido Mr. Mikoyan!”, p. 802.

76 Pettiná, “¡Bienvenido Mr. Mikoyan!”, p. 807.

77 Roces, “Cuba, desde Roma”, p. 21.

78 "Exposición mexicana en el Museo Pushkin de Moscú"; "México en la Unión Soviética”.
} 
paz" ${ }^{79}$ Asimismo, en un ensayo plagado de ambigüedades acerca de esta cuestión publicado en Política en 1961, Carlos Fuentes se preguntaba si los pueblos del Tercer Mundo podrían emprender movimientos de liberación que preservaran los principios democráticos. Consideraba que si bien "la URSS no tenía otra salida que la aplicada por Stalin", "la situación internacional [favorecía] la construcción del socialismo en los países subdesarrollados sin caer en los extremos del stalinismo". ${ }^{80}$

Para Flores Olea, los movimientos anticoloniales que habían dado lugar a las revoluciones cubana, indochina, egipcia, congolesa y argelina, representaban "el acontecimiento histórico más importante de esta segunda mitad del siglo". México, afirmaba, debía saber que la sociedad capitalista había "llegado a su ocaso" y que nada podría impedir que el Tercer Mundo rompiera "los viejos sistemas de explotación", por lo que "su futuro, su independencia económica, su democracia, su libertad, se juegan en las luchas de los países pobres". ${ }^{81}$ A su vez, Carlos Fuentes planteaba que se estaba viviendo un momento en el cual la dinámica de los pueblos subdesarrollados se había impuesto a las problemáticas derivadas de la historia de Occidente. ${ }^{82}$

Entre 1961 y 1962 tuvieron lugar dos grandes hechos políticos apoyados por Cárdenas, que reivindicaron los principios tercermundistas y antiimperialistas, dando además un apoyo incondicional a la revolución cubana. ${ }^{83}$ Política fungió como una

79 Flores Olea, "En torno a la Junta Cumbre. Jruschov y los diablos sueltos de la guerra", p. 32.

${ }^{80}$ Fuentes, “Carne y cartón de Stalin”, p. 17.

${ }^{81}$ Flores Olea, “Cuba y su legítima defensa”, pp. 52-53.

82 Fuentes, “Entrevista con Raúl Roa”, p. 28.

83 Soledad Loaeza plantea que, durante la campaña electoral de 1964, Díaz Ordaz vio con mucha preocupación que Cárdenas alentara un movimiento amplio de izquierda que incluyera a las corrientes críticas dentro del PRI, como acababa de suceder en 1962 con la organización del MLN. Considera que, en aquellos años, Díaz Ordaz era más un reformista que un "duro", ya que "había abierto espacios a la oposición partidista mediante la reforma electoral 
plataforma para la organización y la difusión de estos dos actos: la Conferencia Latinoamericana por la Soberanía Nacional, la Emancipación Económica y la Paz, ${ }^{84}$ y el Movimiento de Liberación Nacional (MLN). La Conferencia Latinoamericana tuvo lugar en la ciudad de México en los primeros días de marzo de 1961;85 fue convocada por Lázaro Cárdenas y reunió a representantes de toda América Latina, así como a observadores de los Estados Unidos, la URSS, China y algunos países de África, en el espíritu de la reunión de los países no alineados en Bandung en 1955. ${ }^{86}$ A partir de su participación en el movimiento ferrocarrilero de 1958-1959, escribe Carlos Illades, al inicio de los años sesenta Cárdenas se puso al frente de una coalición de oposición configurada a partir de las alianzas establecidas con un

[...] amplio espectro político que incluía al PCM, el PPs, sindicatos obreros, organizaciones campesinas y segmentos del PRI, con el propósito de constituir un frente democrático que atajara las

que introdujo las diputaciones de partido [y] desde la campaña electoral había apoyado el proyecto de reforma del PRI de Carlos Madrazo, quien llegó a la presidencia del partido en noviembre de 1964”. Loaeza, “Gustavo Díaz Ordaz: el colapso del milagro mexicano", p. 130.

${ }^{84}$ Los Documentos de la Conferencia Latinoamericana se encuentran reunidos en http://www.memoriapoliticademexico.org/Textos/6Revolucion/1961D-CLASNEEP. html Originalmente fueron publicados en Política (1a abr. 1961), año I, núm. 23, pp. I-XLVIII.

${ }^{85} \mathrm{Su}$ antecedente inmediato fue la Comisión Nacional de Planeación para la Paz, conformada el 15 de febrero de 1944 para estudiar los problemas de México en la posguerra. Véase El Economista.

${ }^{86}$ Enrique González Pedrero subraya el vínculo entre la Conferencia Latinoamericana y la de Bandung, afirmando que ambas buscaban que los llamados países del Tercer Mundo hicieran oír "su propia voz", a fin de crear un mundo "sin analfabetos, sin latifundismo, sin subordinación económico-política, ejerciendo plenamente su soberanía: haciendo una política a favor de las clases que producen, a favor de la historia, del hombre". González Pedrero, "Hacia un Bandung en América Latina”, p. 19. 
políticas represivas del gobierno de Adolfo López Mateos, permitiera la democracia sindical y la libre competencia política. ${ }^{87}$

Entre los delegados mexicanos a la Conferencia Latinoamericana se encontraban varios miembros del equipo de Politica: Carlos Fuentes, Vicente Lombardo Toledano, Fernando Carmona, Enrique González Pedrero, Enrique Ramírez y Ramírez, Ángel Bassols, Francisco López Cámara, Víctor Flores Olea y Eli de Gortari. Todos ellos defendieron la idea de que la unión de los pueblos del Tercer Mundo era la clave del cambio. Carlos Fuentes escribía: “aislados, estamos condenados a lo que hoy vivimos [...] Defender a Cuba y al Congo hoy, defender mañana a Guinea y a la RAU, defender pasado mañana a Rodesia y a Angola, es defendernos a nosotros mismos. Así lo entiende Lázaro Cárdenas y, con él, el pueblo de México". ${ }^{88}$ Y Víctor Flores Olea observaba que México “no puede dejar de solidarizarse con Cuba, con Guinea, con Argelia. Las voces que escuchamos en la Conferencia [Latinoamericana] por la Soberanía Nacional, la Emancipación Económica y la Paz nos recuerdan que no estamos solos" ${ }^{89}$

Al convocar y presidir la Conferencia, Lázaro Cárdenas buscó consolidarse como líder de la izquierda latinoamericana. Al término de la reunión, el expresidente invitó a algunos de los delegados internacionales, así como a intelectuales ligados a Política, a realizar un recorrido por varios estados del centro de la República. En Guanajuato, señalaba Francisco López Cámara, "las masas campesinas estaban abiertamente con la revolución Cubana”, en tanto que los delegados latinoamericanos reconocían en Cárdenas una figura que encarnaba el sentimiento antiimperialista a nivel continental: "no solo [es] el guía indiscutido

87 Illades, “El compromiso de los intelectuales”, p. 35.

88 Fuentes, "Cárdenas en su sitio", p. 17.

89 Flores Olea, “México no está solo”, p. 37. 
del pueblo mexicano [sino el] maestro de todos los pueblos de América Latina"..$^{90}$ Un intelectual oficialista como Abreu Gómez presentaba a Cárdenas como un dirigente o "guía" que, al igual que Fidel, encarnaba la conciencia del pueblo.

Cárdenas es el hombre que ha sentido el pulso de esa vitalidad mexicana y nos dice en cada encrucijada histórica: Por aquí. Y su mano señala el rumbo verdadero, no el rumbo para caminar un día, sino para caminar siglos. De ahí que Cárdenas signifique, en estos días de desequilibrios propios y extraños, la razón de una sobrevivencia y de un resurgimiento social. Por eso, Cárdenas es el héroe de la conciencia nacional. ${ }^{91}$

En un texto acerca de la Guerra Fría y la historiografía política mexicana en la posguerra, Ariel Rodríguez Kuri propuso que durante este periodo el conflicto interno de las élites en el poder estuvo regulado por sus posicionamientos abstractos acerca de la soberanía y la autodeterminación de los pueblos en el ámbito internacional. Para este autor, la "política exterior [fue] una faceta de la interior" y las tensiones entre los grupos políticos que estaban detrás de Alemán y Cárdenas -en este caso habría que añadir a López Mateos- estuvieron ligadas a las proyecciones que unos y otros buscaron irradiar hacia el extranjero. ${ }^{22} \mathrm{El}$ caso de Cárdenas durante la Conferencia Latinoamericana, y después durante la formación del MLN, ilustra bien este fenómeno. El expresidente buscó reposicionarse políticamente y afianzar un equilibrio interno de fuerzas mediante una retórica tercermundista, anticolonialista y de apoyo a la revolución cubana, que estaba circulando a nivel internacional.

90 López Cámara, "La gira de la amistad”, pp. 10-11. Véase también Fuentes, "Querétaro, Guanajuato, Jalisco y Michoacán".

91 Abreu Gómez, “Cárdenas, héroe de la conciencia nacional”, p. 23 (las cursivas aparecen en el original).

92 Rodríguez Kuri, “México: Guerra Fría e historia política”, p. 650. 
A partir de las discusiones que tuvieron lugar en la Conferencia Latinoamericana, en agosto del mismo año surgió la idea de convocar a un Movimiento de Liberación Nacional. ${ }^{93} \mathrm{El}$ MLN nació en 1961 y se desintegró en 1964. Su propósito inicial fue unir las diferentes vertientes de la izquierda mexicana mediante la organización de "los sectores democráticos dispuestos a luchar por el desarrollo independiente del país, en torno a un programa nacional contra el imperialismo extranjero y en defensa de los intereses del pueblo mexicano". ${ }^{94}$ En un primer momento, el Movimiento agrupó a comunistas y cardenistas dentro de un mismo frente político nacionalista que albergó corrientes y perfiles muy heterogéneos. La izquierda, escribe Barry Carr,

[...] estuvo representada [por] la mayoría de los partidos socialistas existentes [el PCM y el PPS] y una gran parte de las personalidades intelectuales, políticas y culturales que podían llamarse "cardenistas", "progresistas" o "liberales". Entre los intelectuales, se hallaban socialistas independientes como Narciso Bassols y una nueva generación de artistas y escritores como Carlos Fuentes, y académicos y profesionistas como Eli de Gortari y Heberto Castillo. ${ }^{95}$

${ }_{93}$ En 1971, Carlos Fuentes presentó este balance del contexto en el que surge el MLN: "La corrupción radical del movimiento obrero durante el alemanismo, las luchas obreras de 1958 y 1959, la represión brutal contra el sindicato ferrocarrilero de Demetrio Vallejo, el asesinato del dirigente campesino Rubén Jaramillo, la solidaridad con Cuba, y por encima de todo, el aplazamiento de las reformas revolucionarias y el deterioro de las condiciones de vida y de trabajo de la mayoría de los mexicanos (efecto previsible del aplazamiento de la Revolución) se sumaron para impulsar la decisión de organizar a las fuerzas de la izquierda mexicana en el Movimiento de Liberación Nacional. Al ser creado, este Movimiento contó con la presencia de Lázaro Cárdenas, conciencia perturbadora de los 'revolucionarios' de mentiras, hombre de principios en nación de oportunistas". Fuentes, "Radiografía de una década, 1953-1963", pp. 86-87.

94 “Programa del Movimiento de Liberación Nacional”, p. i.

95 CARr, "El nacimiento de una nueva izquierda, 1960-1975", pp. 236-237. 
La plataforma ideológica del MLN fue elaborada por los escritores y científicos sociales reunidos en Política a partir de los ideales de la revolución cubana, la rearticulación de un programa de reforma agraria de corte cardenista, la liberación de los presos políticos del movimiento ferrocarrilero y la defensa de la soberanía nacional. ${ }^{96}$ En consonancia con la Conferencia Latinoamericana, el MLN buscó establecer lazos de solidaridad con los movimientos anticoloniales y antiimperialistas de Latinoamérica, Asia y África.

A su vez, el presidente López Mateos también dio su apoyo a Cuba y se manifestó en favor de los países del Tercer Mundo. Este discurso, señala Renata Keller, obedeció a la necesidad de contener el descontento interno y reafirmar el legado de la revolución mexicana; sin embargo, en materia de política internacional López Mateos se apegó a las consignas estadounidenses de aislar a Cuba. ${ }^{97}$ Esta ambigüedad o doble juego por parte del gobierno mexicano estuvo en el origen de las fuertes tensiones entre López Mateos y la revista Política, que, además de publicar innumerables textos en favor del MLN y de los principios tercermundistas, comenzó a denunciar abiertamente el buen entendimiento entre el presidente y la administración estadounidense. De esta denuncia en materia de política internacional se pasó a una denuncia de la política interna y del vacío que reinaba en las instituciones. De manera que un autor como Víctor Flores Olea llamaba al pueblo

[...] a volver sobre sí mismo, aglutinarse y organizarse [para] constituir de nueva cuenta un cuerpo político capaz de sustituir, llegada la oportunidad, al aparato caduco y descompuesto que nos gobierna [...] el vacío que rige la vida política de México tiene un fin, debe tener un fin. Y llenarlo de contenido, de democracia, de honradez,

\footnotetext{
96 "Llamamiento del Movimiento de Liberación Nacional", cuarta de forros. 97 Keller, Mexico's Cold War, pp. 6-7.
} 
de sentido popular es el gran imperativo revolucionario que ha de cumplir México en los próximos años. ${ }^{98}$

En el seno del MLN, la corriente representada por Vicente Lombardo Toledano, el prs, y el periódico El Día, respaldó la posición gubernamental en el sentido de acotar los alcances del Movimiento. Barry Carr define a Lombardo Toledano y su grupo como una "izquierda leal", que "atacó las aspiraciones radicales de la 'izquierda' del MLN (y expulsó a aquellos de sus miembros que permanecían en la organización, como el doctor Jorge Carrión y el propietario y director de Política, Manuel Marcué Pardiñas)" ${ }^{99}$ La interpretación de Carr es que el pps y su líder desplegaron un "creativo oportunismo" que permitió "hacer malabarismos con un extraordinario número de corrientes políticas e ideológicas, como el cardenismo, la solidaridad con la Revolución cubana y la tradicional simpatía por la Unión Soviética”. ${ }^{100}$

Además de la escisión generada por la posición oficialista respaldada por Lombardo dentro del MLN, la proximidad de las elecciones de 1964 fue otro factor que influyó en el debilitamiento del Movimiento. El Partido Comunista y sus aliados se radicalizaron y apoyaron la candidatura de Ramón Danzós Palomino por medio del Frente Electoral del Pueblo, mientras que el grupo encabezado por Lázaro Cárdenas rechazó competir en el juego electoral. En realidad, escribe Soledad Loaeza, Cárdenas "seguía siendo miembro de la Revolución institucionalizada y su compromiso con la nueva izquierda era limitado $[. .$.$] no estuvo dispuesto a llevar hasta sus últimas con-$ secuencias la incomodidad que le causaban las políticas de sus sucesores, llámese Miguel Alemán o Adolfo Ruiz Cortines”. ${ }^{101}$

98 Flores Olea, “La política del vacío”, p. 39.

99 CARr, “El nacimiento de una nueva izquierda, 1960-1975”, p. 237.

100 CARr, “El nacimiento de una nueva izquierda, 1960-1975”, p. 237.

101 Loaeza, “Gustavo Díaz Ordaz: el colapso del milagro mexicano”, p. 140. 
El distanciamiento entre el Partido Comunista y los cardenistas en 1964 coincidió con la salida de Política -y del MLN- de Fernando Benítez, Víctor Flores Olea, Carlos Fuentes, Enrique González Pedrero y Francisco López Cámara, a quienes Manuel Marcué Pardiñas calificó de "miedosos”, "ambiguos” y sin compromiso verdadero, considerando que su renuncia había sido un acto de oportunismo por parte de "intelectuales orgánicos que se acercan y se alejan del príncipe según las circunstancias políticas". ${ }^{102}$ Otra ruptura, que repercutió tanto sobre Política como sobre el MLN, se produjo en 1965 con la salida de Alonso Aguilar, Fernando Carmona y Enrique Ramírez y Ramírez, que más tarde animaron la revista Estrategia. Según el testimonio de Marcué Pardiñas, Cárdenas lamentó que estos últimos se hubieran separado del MLN, dejando la dirección en manos de Heberto Castillo, Manuel Terrazas y otros cuadros medios del Movimiento. ${ }^{103}$

En un excelente trabajo, el historiador estadounidense Patrick Iber ha establecido un vínculo directo entre la revista Política y el desarrollo del MLN, identificando una serie de "ironías" o contradicciones que marcaron la historia del movimiento político y que se reflejaron en la trayectoria de la revista. La primera de ellas es que el cardenismo de los años sesenta no era compatible con el de los años treinta, cuya tendencia centralizadora favoreció la creación de empresas paraestatales como PIPSA que fue el instrumento del cual se valió el gobierno para eliminar a Política. La segunda es que el MLN vio en Cuba un modelo político ejemplar en un momento en que dicho país construía instituciones represivas. En tercer lugar que, a partir de su encarcelamiento, un estalinista como Siqueiros se convirtiera en el símbolo de la libertad de expresión. En cuarto lugar, es que, en el contexto de la Guerra Fría cultural, el MLN buscara hacer surgir un

102 Perzabal, De las memorias de Manuel Marcué Pardiñas, pp. 49-50.

103 Perzabal, De las memorias de Manuel Marcué Pardiñas, p. 30. 
movimiento en favor de la democracia estableciendo alianzas con grupos prosoviéticos, pensando que de esta alianza podía resultar un movimiento político independiente con carácter nacional. Por último, Iber apunta una serie de contradicciones que se sitúan en un segundo plano, pero que no dejan de ser significativas: el MLN ejerció presiones para que México entablara relaciones diplomáticas con Cuba y, a fin de que este vínculo se consolidara, Cuba no apoyó la insurgencia en México en tanto que sostenía movimientos armados en otras regiones de América Latina; mientras los presidentes mexicanos estaban en la nómina de la CIA, el jefe del servicio de inteligencia mexicano estrechaba una amistad con Fidel Castro; los Estados Unidos dependieron cada vez más de la alianza cubano-mexicana para obtener información acerca de los acontecimientos cubanos, así como los de la región caribeña y centroamericana. Iber concluye que las repercusiones más importantes del MLN no correspondieron con lo que fueron sus intenciones iniciales. ${ }^{104}$

\section{CONCLUSIONES}

El hecho de que la invasión soviética a Checoeslovaquia en 1968 fuera avalada por Fidel Castro, y de que éste hubiera apoyado la reacción del gobierno mexicano ante el movimiento estudiantil ese mismo año, abre interrogantes acerca de la ausencia de una reflexión crítica por una parte mayoritaria de la izquierda mexicana de los años setenta y ochenta sobre muchos de los temas abordados en Política años atrás. Si bien la generación de jóvenes intelectuales que conformó la Nueva Izquierda puso sobre la mesa el tema de la necesidad de llevar a cabo una autocrítica, ${ }^{105}$

104 IBER, Neither Peace Nor Freedom, pp. 172-173.

105 En 1984 el escritor Héctor Manjarrez publicó en Cuadernos Políticos un artículo importante acerca de las posturas adoptadas por Cortázar ante la revolución cubana, en el cual subrayaba que "el silenciamiento de las dificultades y los errores de la izquierda -en el poder o fuera de él- equivale simple 
una parte sustancial de la izquierda siguió apegada a los viejos argumentos en relación con Cuba, el tercermundismo y el antiimperialismo. Al inicio de los años ochenta Adolfo Gilly reiteraba, por ejemplo, que Cuba había abierto la posibilidad de interpretar la revolución mexicana:

Los años sesenta trajeron un cambio radical. Una nueva revolución latinoamericana, la revolución cubana, estaba en auge y cubría con la sombra que proyectaban sus audacias y sus conquistas el brillo y la gloria ya antiguos y opacados de la entonces cincuentenaria revolución mexicana. La cubana, yendo aún más lejos en sus proyectos, sus realizaciones y sus desafíos, obligaba a la revisión de los límites históricos de la mexicana. ${ }^{106}$

Incluso revistas con una orientación crítica e innovadora, como El Buscón, contrastaron los años sesenta con los setenta y percibieron estos últimos como un periodo marcado por el desencanto y el desánimo, a pesar de que durante la década de los setenta aparecieron periódicos y revistas de gran creatividad, como Excelsior y Plural, que transformaron el panorama político y cultural de México. La apreciación de El Buscón es la siguiente:

Una simple constatación: si en los sesenta los jóvenes vivieron la política como forma posible de existencia cotidiana, en la década

y sencillamente a [...] llevar agua al molino de la burguesía. Mientras la crítica de la izquierda y del socialismo esté en manos de los liberales y los 'renegados', como hasta ahora lo ha estado mayoritariamente, la esperanza tan cara a Cortázar será tanto más inaccesible [...] Sin autocrítica -la historia lo demuestra hasta el hartazgo- sobran los 'renegados' y la esperanza es muy poco creativa”. Manjarrez, “La revolución y el escritor según Cortázar”, p. 158. En esos mismos años, Roger Bartra dirigió también una crítica a la izquierda ortodoxa, argumentando a favor de construir un socialismo abierto y democrático. BARTRA, “Nuestro 1984".

106 GILly, “México contemporáneo: revolución e historia”, p. 17. 
de los setenta optaron por distanciarse de ella. "De la toma del cielo por asalto, a la toma del cielo por etapas, a la renuncia del cielo" podría ser el título de una historia, que separa la generación del 68 de la generación del 82. O bien: de la política como arte lúdico a la política de los profesionalismos administradores. Generación del desencanto se ha llamado a los que vivieron bajo la sombra del retorno del espíritu del 68 y obtuvieron un páramo de reformas siempre deseables- certeramente dosificadas. Ilusiones evaporadas: los setentas comienzan con la consigna de abajo-todos-los mitos y terminan con un débil y difuso llamado a la cordura, la ecuanimidad y la tolerancia. Una mutación de esta magnitud merece, por lo menos, una reflexión de sus protagonistas y sus víctimas. ${ }^{107}$

¿Se “evaporaron las ilusiones”, como lo afirma este artículo de El Buscón, o bien las izquierdas de los años sesenta legaron una propuesta muy ideologizada, que no fue objeto de una crítica y de la cual fue difícil desprenderse posteriormente? La balanza se inclinaría hacia la segunda de estas opciones si se consideran los siguientes elementos. A pesar de las declaraciones reiteradas acerca del compromiso de los intelectuales con el “pueblo", el nacionalismo revolucionario presente en una revista como Política no entabló vínculos con movimientos sociales más amplios. Barry Carr señala en este sentido que el MLN no "logró atraerse a las grandes organizaciones obreras. Esto reflejaba la preferencia del MLN por incorporar individuos más que organizaciones" ${ }^{108}$ Politica fue una revista hecha por intelectuales que, salvo algunas excepciones, estuvieron desvinculados de movimientos sociales más amplios. Fernando Benítez lo expresa claramente: los intelectuales contestatarios, dice, conformaban un “pequeñísimo grupo” preocupado “vivamente por el destino

107 Editorial s/f, "Un, dos, tres, un, dos, tres, calabaza. ¿Jugamos a los desencantados?”, p. 82.

108 CARr, "El nacimiento de una nueva izquierda, 1960-1975", p. 237. 
de su patria". Personalmente, reiteraba esta aspiración abstracta al patriotismo:

Mi vida entera, mis libros, mis escritos tienen la suprema aspiración de luchar por el pueblo, de señalar males que pueden ser remediados antes de que una ola de violencia nos hunda en un caos de ruinas y de sangre; aspiran a que los mejores de mi país, los más honrados, reconozcan que si merezco un «ismo» éste es el «ismo» honroso que lleva consigo el patriotismo. ${ }^{109}$

En una reflexión acerca de la actuación de una parte de la izquierda francesa en el momento de la guerra de Argelia (19541962), Claude Lefort examinó la postura de los intelectuales que "pensaron" en la revolución pero cuya "actuación" fue mínima. ${ }^{110}$ En un artículo publicado en 1963 sostuvo que estos intelectuales fueron "espectadores" a la espera de grandes acontecimientos políticos, y cuya "pasión revolucionaria" fue poco tolerante hacia la duda en la medida en que cualquier cuestionamiento era interpretado como una forma de complicidad con la opresión. Detrás del apoyo incondicional que una parte de la izquierda francesa de los años sesenta dio a las luchas tercermundistas, Lefort identifica un desplazamiento de la problemática del movimiento obrero francés hacia las revoluciones triunfantes en Cuba, Guinea, Argelia o China, y constata la incapacidad por parte de los "intelectuales progresistas", como Sartre, de establecer una diferenciación entre dos realidades que desde ningún punto de vista eran equiparables. En torno del mismo punto, Kolakowski considera "increíble que el culto al primitivismo, aunado a la creencia de que la renovación de la humanidad proviene de las sociedades menos desarrolladas, pudiera aparecer como una formulación marxista”. Una cosa,

109 Benítez, “¿Cuál izquierda?”, p. 43.

110 Lefort, “La politique et la pensé de la politique”, pp. 48-50. 
dice, "es tomar partido a favor de los estratos más desfavorecidos de una sociedad y apoyar sus esfuerzos para superar la miseria y la humillación, y algo muy diferente es aprobar cualquier tipo de barbarie y de violencia si provienen de los grupos discriminados". ${ }^{111}$ Las observaciones de Leszek Kolakowski y de Claude Lefort se aplican al caso de México, en donde la corriente tercermundista fue también intransigente y suplantó, junto con el maoísmo, la adhesión incondicional al sovietismo.

Si bien el entusiasmo generado por la revolución cubana provocó fuertes reacciones en la derecha mexicana, los intelectuales reunidos en Política a principios de los años sesenta asociaron cualquier forma de cuestionamiento sobre el castrismo o la propuesta tercermundista con ideologías reaccionarias y anticomunistas. Las influencias extranjeras que fueron admitidas provinieron de autores como Sartre y C. W. Mills, dejando de lado o ignorando las reflexiones críticas acerca del fenómeno totalitario que a partir de los años cincuenta estaban siendo debatidas por otras tendencias de la izquierda europea. Dos críticos del marxismo ortodoxo, como Leszek Kolakowski y Kostas Papaioannou -cercanos a Claude Lefort y a Cornelius Castoriadis-, fueron leídos y difundidos por medio de Plural (1971-1976), el suplemento cultural de Excelsior dirigido por Octavio Paz que abrió el debate acerca del rumbo que tomaba la revolución cubana y denunció la ceguera ante el fenómeno totalitario en la URSS. ${ }^{112}$ Este debate tuvo, sin embargo, lugar en el seno de círculos minoritarios y no alcanzó a sentar las bases de un pensamiento crítico dentro de la izquierda.

Quedan abiertas muchas interrogantes acerca de si el desarrollo de un pensamiento crítico en la izquierda después del 68 hubiera permitido considerar desde otra óptica fenómenos como la irrupción de la guerrilla, la crisis del "socialismo real"

111 KolakowsKi, “Les intellectuels contre l'intellect”, pp. 83-84.

112 KING, Plural en la cultura literaria y política mexicana, p. 175. 
y del marxismo, así como la cooptación de algunos escritores contestatarios por parte del echeverrismo. Acerca de este último punto vale la pena recordar que en 1972 dos de las figuras emblemáticas del nacionalismo de izquierda durante los años sesenta, que entre 1960 y 1964 habían sido quizá los miembros más activos y beligerantes de la revista Política-Fernando Benítez y Carlos Fuentes-, llamaron a apoyar incondicionalmente al régimen de Echeverría. ${ }^{113}$ Este hecho da cuenta de la naturaleza efímera de las alianzas que las izquierdas entablaron con el nacionalismo revolucionario durante la segunda mitad del siglo xx, así como de las contradicciones que esto entrañó.

\section{REFERENCIAS}

Abreu Gómez, Ermilo, “Cárdenas, héroe de la conciencia nacional”, en Política (15 sep. 1961), año II, núm. 34, p. 23.

Arreola, Juan José, “Por qué estoy con Cuba”, en Política (15 mar. 1961), año I, núm. 22, pp. 34-35.

BARTRA, Roger, “Nuestro 1984”, en Nexos (1ํmar. 1984).

Benítez, Fernando, "La batalla de Cuba", en La batalla de Cuba, con un ensayo de Enrique González Pedrero, "Fisonomía de Cuba", México, Ediciones Era, 1960, pp. 9-139.

BeníTEz, Fernando, "Cuba: la prueba de fuego para Estados Unidos o la parábola de David y Goliat”, en Política (1- mayo 1960), año I, núm. 1, pp. 40-42.

Benítez, Fernando, "La libertad de prensa no es la libertad de venderse al mejor postor”, en Política (1o jun. 1960), año I, núm. 3, pp. 16-20.

Benítez, Fernando, “Como en 1910...", en Política (10 ene. 1961), año I, núm. p. 17.

113 KIng, Plural en la cultura literaria y politica mexicana, pp. 129-130. Acerca de la justificación presentada por Fuentes y del debate que la decisión de Benítez y de Fuentes generó en el mundo intelectual véase KING, Plural en la cultura literaria y política mexicana, pp. 130-137. 
Benítez, Fernando, “¿Cuál izquierda?”, en Política (15 jun. 1961), año II, núm. 28, p. 43.

Benítez, Fernando, Lázaro Cárdenas y la Revolución mexicana. III. El cardenismo, México, Fondo de Cultura Económica, 1978.

CARR, Barry, “El nacimiento de una nueva izquierda, 1960-1975”, en $L a$ izquierda mexicana a través del siglo XX, México, Ediciones Era, 1996, pp. 229-259.

Carrión, Jorge, “Cuba, revolución sin maracas”, en Política (15 mayo 1960), año I, núm. 2, p. 16.

Chávez Mancilla, Ángel, "De la Nicolaíta al 68. Eli de Gortari y la protesta universitaria”, en Signos Históricos, xIx: 37 (ene.-jun. 2017), pp. 127-155.

“Declaración de los Pueblos”, La Habana, 26 de enero de 1962, en Política (1으 feb. 1962), año II, núm. 43, p. 30.

"Documentos de la Conferencia Latinoamericana por la Soberanía Nacional, la Emancipación Económica y la Paz", Política. Quince días de México y del Mundo (1o abr. 1961), año I, núm. 23, pp. I-XLVIII. http://www.memoriapoliticademexico.org/Textos/6Revolucion/1961-D-CLASNEEP.html

Editorial s/f, "Nuestro compromiso", en Política (1o mayo 1960), año I, núm. 1, p. 2.

Editorial s/f, "Dos años de Política”, en Política (1ㅇ mayo 1962), año II, núm. 49 , contraportada.

Editorial s/f, "Un, dos, tres, un, dos, tres, calabaza. ¿Jugamos a los desencantados?”, en El Buscón, núm. 1 (nov.-dic. 1982), p. 82.

El Economista, tomo XI, año 6 (16 mar. 1944).

El Machete. Revista mensual de cultura política, 1980-1981, edición facsimilar, México, Fondo de Cultura Económica, Instituto Nacional de Antropología e Historia, La Jaula Abierta, 2016.

Enríquez Perea, Alberto, "En Política: El periodismo militante de Carlos Fuentes”, en Nexos, núm. 370, año 31, vol. xxx (oct. 2008), pp. 65-72.

"Exposición mexicana en el Museo Pushkin de Moscú”, en Política (1 dic. 1960), año I, núm. 15. 
Flores Olea, Víctor, “Cuba, una democracia concreta”, en Política (15 mayo 1960), año I, núm. 2, p. 10.

Flores Olea, Víctor, "En torno a la Junta Cumbre. Jruschov y los diablos sueltos de la guerra”, en Política (1o jun. 1960), año I, núm. 3, pp. 32-33.

Flores Olea, Víctor, “Cuba y su legítima defensa”, en Política (1a ago. 1960), año I, núm. 7, pp. 52-53.

Flores Olea, Víctor, “La revolución traicionada”, en Política (15 feb. 1961), año I, núm. 20, pp. 36-37.

Flores Olea, Víctor, “México no está solo”, en Política (15 mar. 1961), año I, núm. 22, p. 37.

Flores Olea, Víctor, “La política del vacío”, en Política (1a abr. 1961), año I, núm. 23, p. 39.

Fuentes, Carlos, "Primero de mayo en La Habana", en Política (15 mayo 1960), año I, núm. 2, p. 46.

Fuentes, Carlos, "El pueblo puede 'saltar las trancas”, en Política (1o jul. 1960), año I, núm. 5, p. 23.

Fuentes, Carlos, “Entrevista con Raúl Roa”, Nueva York, noviembre de 1960, Política (1ํo dic. 1960), año I, núm. 15, p. 28.

Fuentes, Carlos, “Guerrero: ¿quién es el responsable?”, en Política (1으e ene. 1961), año I, núm. 17, p. 25.

Fuentes, Carlos, “Cárdenas en su sitio”, en Política (1 mar. 1961), año I, núm. 21, p. 17.

Fuentes, Carlos, “Querétaro, Guanajuato, Jalisco y Michoacán”, en Política (1o abr. 1961), año I, núm. 23, pp. 15-22.

Fuentes, Carlos, "Con el fascismo o con el pueblo. La hora de la definición”, en Política (1omayo 1961), año I, núm. 25, pp. 10-11.

Fuentes, Carlos, “De Bandung a Belgrado”, en Política (15 sep. 1961), año II, núm. 34, pp. 16-19.

Fuentes, Carlos, “Carne y cartón de Stalin”, en Política (1ํ nov. 1961), año II, núm. 37, p. 17. 
Fuentes, Carlos, “Radiografía de una década, 1953-1963”, en Tiempo mexicano, México, Cuadernos de Joaquín Mortiz, 1971.

FuENTEs, Carlos, "Regreso al hogar. Mi casa veracruzana”, Discurso pronunciado en el Ayuntamiento de Jalapa como homenaje póstumo al embajador Rafael Fuentes y en el que se declaró Hijo Predilecto de Jalapa y ciudadano veracruzano por nacimiento a Carlos Fuentes, en Nuevo tiempo mexicano, México, Aguilar, 1994.

GILly, Adolfo, “México contemporáneo: revolución e historia”, en Nexos, núm. 62 (feb. 1983), p. 17.

González Pedrero, Enrique, "Hacia un Bandung en América Latina”, en Política (1ำ feb. 1961), año I, núm. 19, p. 19.

González Pedrero, Enrique, "La crisis llega al Pri”, en Política (15 abr. 1961), año I, núm. 24.

Gosse, Van, “A Movement of Movements: The Definition and Periodization of the New Left”, en Jean-Christophe Agnew y Roy Rosenzweig (eds.), A Companion to Post-1945 America, Londres, Blackwell, 2002, pp. 277-302.

Gould, Jeffrey, “Solidarity under Siege: The Latin American Left, 1968”, en The American Historical Review, 114: 2 (abr. 2009), pp. 348-375.

Hurtado, Guillermo, “Un antecedente de El Espectador: críticas a la Revolución mexicana en 1959”, en Literatura mexicana, 21: 2 (2010).

Iber, Patrick, Neither Peace Nor Freedom. The Cultural Cold War in Latin America, Cambridge, Londres, Harvard University Press, 2015.

Illades, Carlos, "El compromiso de los intelectuales", en La inteligencia rebelde: la izquierda en el debate público de México, 1968-1989, México, Oceano, 2012.

Judt, Tony, Postguerra. Una historia de Europa desde 1945, México, Taurus Historia, 2011.

Keller, Renata, Mexico's Cold War. Cuba, the United States, and the Legacy of the Mexican Revolution, Nueva York, Cambridge University Press, 2015.

KING, John, Plural en la cultura literaria y política latinoamericana. De Tlateloloco a "El ogro filantrópico", México, Fondo de Cultura Económica, 2011. 
KolaKowsKi, Leszek, “Les intellectuels contre l'intellect” (1972), en L'esprit révolutionnaire suivi de Marxisme: utopie et anti-utopie, Bruselas, Éditions Complexe, 1974, pp. 64-89.

Krauze, Enrique, "Cuatro estaciones de la cultura mexicana”, en Vuelta, núm. 60 (nov. 1981).

LEFORT, Claude, "La méthode des intellectuels progressistes" (1958), Éléments d'une critique de la bureaucratie, París, Gallimard, 1979, pp. 236-268. Publicado inicialmente en Socialisme ou Barbarie, 23 (ene.-feb. 1958).

LEFORT, Claude, “Le nouveau et l'attrait de la répétition” (1970), en Éléments d'une critique de la bureaucratie, París, Gallimard, 1979, pp. 355-371.

Lefort, Claude, "La politique et la pensé de la politique" (1963), en Sur une colonne absente. Écrits autour de Merleau-Ponty, París, Gallimard, Les Essais CCIV, 1978, pp. 45-104.

"Llamamiento del Movimiento de Liberación Nacional”, en Política (1ํago. 1961), año II, núm. 32, contraportada y cuarta de forros.

Loaeza, Soledad, "Gustavo Díaz Ordaz: el colapso del milagro mexicano", en Ilán Bizberg y Lorenzo Meyer (coords.), Una historia contemporánea de México, México, Oceano, 2005, pp. 117-155.

López Cámara, Francisco, “¿Está muerta la revolución mexicana?”, en Política (15 nov. 1960), año I, núm. 13, p. 31.

López Cámara, Francisco, "La gira de la amistad”, en Política (15 abr. 1961), año I, núm. 24, pp. 10-11.

"Manifiesto del Círculo de Estudios Mexicanos A. C. a favor de Cuba", en Política (1o ago. 1960), año I, núm. 7, pp. 15-17.

Manjarrez, Héctor, “La revolución y el escritor según Cortázar”, en El camino de los sentimientos, México, Ediciones Era, 1990, pp. 111-168. [Este artículo fue publicado originalmente en Cuadernos Políticos, revista trimestral publicada por Ediciones Era, núm. 41, julio-diciembre, México, 1984, pp. 84-109.]

Marcué Pardiñas, Manuel, y Jorge Carrión, "Problemas con PiPsa", en Política (1o nov. 1960), año I, núm. 13, contraportada. 
"México en la Unión Soviética. La exposición El arte mexicano desde los tiempos precolombinos a nuestros días", en Política (15 dic. 1960), año I, núm. 16, p. 53.

Moya, Rodrigo, “Con los ojos bien abiertos. El reportaje”, en (comps y eds.), Patricia Gola y Alejandra Pérez Zamudio, El telescopio interior, México, Conaculta-Centro de la Imagen, 2014, pp. 109-110.

Pensado, Jaime, Rebel Mexico. Student Unrest and Authoritarian Political Culture During the Long Sixties, Stanford, Stanford University Press, 2013.

Perzabal, Carlos, De las memorias de Manuel Marcué Pardiñas, México, Editorial Rino, 1997.

Pettinà, Vanni, “ßBienvenido Mr. Mikoyan!: tacos y tractores a la sombra del acercamiento soviético- mexicano, 1958-1964”, en dossier México: Guerra Fría e historia política, en Historia Mexicana, Lxvi: 2 (262) (oct.-dic. 2016), pp. 793-852.

Pozas Horcasitas, Ricardo, "El final del horizonte: la muerte simbólica de la Revolución mexicana", en Los límites del presidencialismo en las sociedades complejas. México en los años sesenta, México, Siglo Veintiuno Editores, Universidad Nacional Autónoma de México, 2014, pp. 25-53.

"Programa del Movimiento de Liberación Nacional”, en Política (15 sep. 1961), año II, núm. 34, p. I.

Quesada, Marta, "Jorge Carrión y la revista Política”, en La Jornada Semanal, núm. 975 (10 nov. 2013), pp. 1-3. http://www.jornada.unam.mx/2013/11/10/ sem-marta.html

Reyes Pérez, José Carlos, 'El sueño mayor de hacer libros'. era: cultura escrita en español y la difusión de las ciencias sociales a través de una editorial. 1960-1989", tesis de maestría en historia internacional, Centro de Investigación y Docencia Económicas, México, 2016.

Reynaga Mejía, Juan Rafael, La Revolución cubana en México a través de la revista Política: construcción imaginaria de un discurso para América Latina, México, Universidad Autónoma del Estado de México, Universidad Nacional Autónoma de México, 2007.

Roces, Wenceslao, “Cuba, desde Roma”, en Política (15 mayo 1961), año II, núm. 26, p. 21. 
Rodríguez, Ana Sofía, y Luciano Concheiro, "Nueva izquierda: una revista estudiantil”, en Nexos, La rotativa. Arqueología de la vida intelectual (12 mayo 2014).

Rodríguez Kuri, Ariel, "México: Guerra Fría e historia política”, dossier México: Guerra Fría e historia política, en Historia Mexicana, Lxvi: 2 (262) (oct.-dic. 2016), pp. 645-652.

Rojas, Rafael, Traductores de la utopía. La revolución cubana y la nueva izquierda de Nueva York, México, Fondo de Cultura Económica, 2016.

Santos Ruíz, Ana, Los hijos de los dioses. El Grupo filosófico Hiperión y la filosofía de lo mexicano, México, Bonilla Artigas Editores, 2015.

Santos Valdés, José, “Bailando con Don Porfirio”, en Política (15 mar. 1962), año II, núm. 46, p. 28.

SARTRE, Jean-Paul, “Ouragan sur le sucre”, Les Temps Modernes, 2008/3, núm. 649, París, Gallimard, pp. 5-155. http://www.cairn.info/revue-les-tempsmodernes-2008-page-5.htm

SARTre, Jean-Paul, “Préface à l'édition de 1961”, en Franzt Fanon, Les damnés de la terre, prefacio de Alice Cherki y epílogo de Mohammed Harbi (2002), París, La Découverte \& Syros, 2002, pp. 17-36.

Uranga, Emilio, “Confesión necesaria”, en Política (1ำ ene. 1961), año I, núm. 17, p. 35.

VerdÉs-LeRoux, Jeannine, La lune et le caudillo. Le rêve des intellectuels et le régime cubain (1959-1971), París, Éditions Gallimard, 1989.

Zolov, Eric, "Expanding our Conceptual Horizons: The Shift from an Old to a New Left in Latin America", A Contracorriente. Una revista de historia social y literatura de América Latina, 5: 2 (invierno 2008), pp. 47-73.

Zolov, Eric, "Latin America in the Global Sixties", The Americas, 70: 3 (ene. 2014), pp. 349-362.

OTRAS FUENTES

Conversación con Rodrigo Moya, Cuernavaca, noviembre de 2017. 